\title{
Rancang Bangun Sistem Kolaborasi UKM Berdasarkan Manajemen Rantai Pasok untuk Peningkatan Daya Saing UMKM Kota Semarang
}

\author{
Mustafa \\ Universitas Islam Sultan Agung \\ cakmustafa@unissula.ac.id
}

\begin{abstract}
SME'S competitiveness is a priority program from Semarang Government. Some SME'S obstacles to increase competitiveness consisting of market access, efficient of production and distribution as well as capital access. This study aims to design a system of collaboration between SMEs in the Semarang City based on the supply chain management. Stages of system design ; Requirement analysis, design, programming and system testing. Researchers conduct survey and discussion with SME'S and Stakeholders. The results of the study, Semarang City Government has program to encourage SME'S collaboration in clusters program but it is not going well. Limited information for collaboration is a major obstacle for SMEs to collaborate. $S M E^{\prime} S$ collaboration system based on the supply chain manajemen is a solution for collaborating between SMEs. The most important thing in collaboration system is the fulfillment of raw materials and logistic management. Openness of SMEs to fill SME collaboration system data is a basic requirement so that this SME collaboration system provides maximum benefits.
\end{abstract}

Keyword : SME'S competitiveness, Collaboration, Supply Chain Management, Information System

\begin{abstract}
Abstrak
Peningkatan daya saing UKM menjadi prioritas pengembangan UKM Kota Semarang. Beberapa kendala UKM untuk meningkatkan daya saing diantarnya keterbatasan akses pasar, efisienai produksi dan distribusi serta akses permodalan. Penelitian ini bertujuan melakukan rancang bangun sistem kolaborasi antar pelaku UKM di Kota Semarang berdasarkan manajemen rantai pasok. Tahapan perancangan sistem meliputi identifikasi kebutuhan, desain, pemograman dan pengujian sistem. Identifikasi kebutuhan dilakukan melalui wawancara dengan stakeholder pengembangan UKM. Hasil dari penelitian, sudah ada program Pemkot Semarang mendorong kolaborasi dengan membentuk kluster UKM namun tidak berjalan dengan baik. Keterbatasan informasi untuk saling kerjasama menjadi kendala utama para pelaku UKM berkolaborasi. Sistem kolaborasi UKM Kota Semarang berdasarkan manajemen rantai pasok menjadi solusi untuk berkolaborasi antar pelaku UKM. Kolaborasi paling utama dalam sistem yaitu pada pemenuhan bahan baku dan penggunakan moda transportasi pengiriman produk. Keterbukaan pelaku UMKM untuk mengisi data sistem kolaborasi UKM menjadi syarat pokok supaya sistem kolaborasi UKM ini memberikan manfaat maksimal.
\end{abstract}

Kata Kunci: $\quad$ Daya Saing UKM, Kolaborasi, Manajemen Rantai Pasok, Sistem Informasi 


\section{PENDAHULUAN}

Dari data Dinas Koperasi dan Usaha Kecil dan Menengah Kota Semarang jumlah UKM di kota Semarang terdapat sebanyak 11.331 unit usaha di berbagai sektor. Beberapa kendala yang masih dihadapi para pemilik UKM seperti penentuan strategi mengembangkan bisnis, informasi dan akses pasar, efisiensi jalur distribuai dan akses dalam mendapatkan modal. Permasalah lain dari internal tiap UKM lebih spesifik pada tingkat ketrampilan serta sumber daya manusia yang belum kompeten.

Peningkatan daya saing UKM menjadi salah satu prioritas pegembangan UMKM Kota Semarang karena UMKM memiliki peran penting dalam kebijakan perekonomian Kota Semarang. Salah satu kegiatan untuk meningkatkan daya saing UMKM, sejak 2008 menerapkan program pemberdayaan UMKM berbasis kluster. Munculnya kebijakan Masyarakat Ekonomi ASEAN pada tahun 2015 membuat persaingan pada sektor UKM akan semakin ketat. Melalui MEA maka akan muncul sistem aliran bebas barang, jasa, investasi dan tenaga kerja terampil, serta aliran modal yang lebih bebas. Oleh karena itu, Usaha Kecil dan Menengah (UKM) akan bersaing tidak hanya di dalam negeri saja namun juga bersaing dengan industri di seluruh negara ASEAN.

Untuk meningkatkan daya saing UMKM adalah selalu melakukan inovasi produk yang murah, cepat dan berkualitas dengan memperhatikan manajemen rantai pasok atau Supply
Chain Management (SCM). Aktivitas yang akan dikelola dalam SCM termasuk proses produksi, sistem transportasi/distribusi sampai ke outlet penjualan, gudang, pusat distribusi tempat dimana pengiriman dalam party besar dibagi kedalam party kecil untuk dikirim kembali ke toko-toko dan akhirnya sampai ke retailer yang menjual produk-produk tersebut.

\begin{tabular}{llr}
\multicolumn{2}{c}{ Perkembangan } & \multicolumn{2}{r}{ Teknologi } \\
Informasi dan & \multicolumn{2}{c}{ Komunikasi } \\
memberikan peluang & bagi UMKM \\
untuk meningkatkan daya saing \\
melalui penerapan TIK untuk \\
mendukung proses
\end{tabular}
manajemen distribusi, pemasaran hingga kegiatan customer relationship management (CRM). Selain itu, penerapan TIK untuk UMKM juga bisa dioptimalkan untuk sharing sumber daya dan akses pasar yang menurut pengamatan peneliti sampai saat ini belum bisa berjalan. Penerapan TIK untuk UMKM lebih banyak hanya pada mendukung program pemasaran saja. Belum ada sebuah ide yang memikirkan bagaimana keberlangsungan model model kolaborasi antar UMKM berdasarkan kesesuaian manajemen rantai pasok. Kelemahan yang lain, wadah wadah komunitas bisnis online tersebut tidak difokuskan untuk cluster industri tertentu sehingga meminimalisir peluang untuk berkolaborasi sesama pelaku bisnis dalam sebuah industri.

Oleh sebab itu, untuk meningkatkan daya saing UMKM Kota Semarang, penelitian ini menggagas dibentuknya sebuah ekosistem 
Rancang Bangun Sistem Kolaborasi UKM Berdasarkan Manajemen Rantai Pasok untuk Peningkatan Daya Saing UMKM Kota Semarang

kolaborasi menggunakan TIK yang akan menjadi sarana sharing informasi dan sumber daya antar pelaku UMKM dalam sebuah industri. Model kolaborasi ini didasarkan pada kesesuaian manajemen rantai pasok tiap UMKM.

\section{METODE}

\subsection{Populasi dan Sampel}

Populasi dalam penelitian ini adalah UKM di Kota Semarang dengan prioritas utama bidang Fashion, Kuliner, Retail, Kerajinan dan bidang ICT. Dalam penelitian ini terdapat 55 responden UMKM di Kota Semarang dan stakeholder dari pedamping UKM, DInas Koperasi dan UKM Kota Semarang dan inkubator bisnis

\subsection{Jenis Data}

Data yang digunakan dalam penelitian ini adalah data primer dan data sekunder. Data primer di peroleh melalui penyebaran kuesioner kepada responden terpilih di Kota Semarang. Data sekunder meliputi data-data Dinas Koperasi dan UMKM Kota Semarang, UMKM Center dan datadata lain yang terkait dengan penelitian ini.

\subsection{Analisa data dan Rancang Bangun Sistem}

Pengambilan data melalui isian kuesioner dan wawancara mendalam dengan pelaku UMKM dan stakeholder terkait yang dalam penelitian ini melakukan diskusi dengan pengelola UMKM Center Kota Semarang. Analisis penelitian ini menggunakan analisis deskriptif baik dari analisa data primer maupun sekunder.

Tahapan rancang bangun sistem kolaborasi UKM terdiri dari :

a. Tahap Identifikasi Kebutuhan

Pada tahapan ini akan dilakukan identifikasi kebutuhan sistem kolaborasi UKM Kota Semarang berasarkan manajemen rantai pasok.

\section{b. Tahap Desain Sistem}

Pada tahap ini dilakukan desain business proses, use case, diagram aktivitas, data base dan user interface sistem kolaborasi UKM Kota Semarang.

\section{c. Tahap Pemograman}

Pada tahap ini dilakukan pembuatan kode program sesuai dengan desain sistem.

\section{d. Tahap Uji Coba Aplikasi,}

Dalam tahap ini akan dilakukan ujicoba aplikasi untuk mengetahui apakah sistem dapat berjalan dengan baik.

\section{KERANGKA TEORI}

\subsection{Manajemen Rantai Pasok}

Manajemen Rantai Pasokan atau disebut Supply Chain Management (SCM) merupakan pengelolaan rantai siklus yang lengkap mulai bahan mentah dari para supplier, ke kegiatan operasional di perusahaan, berlanjut ke distribusi sampai kepada konsumen. Manajemen logistik menjadi bagian dalam manajemen rantai pasok karena dalam manajemen rantai pasok terdiri dari merencanakan, mewujudkan dan mengendalikan efisiensi dan efektifitas aliran dan penyimpanan barang dan jasa dan informasi terkait 
antara titik konsumsi untuk memenuhi kebutuhan pelanggan. (Hayati, 2015). Oleh karena itu orientasi utama dari manajemen rantai pasok adalah untuk memenuhi harapan pelanggan, sehingga produk dengan spesifikasi tertentu dapat didistribusikan ke konsumen dengan kualitas tinggi dan biaya yang rendah serta waktu yang tepat (Wahyuniardi et al., 2016).

Sharing informasi dari setiap node pipeline manajemen bisnis UKM mulai dari penyediaan bahan baku, produksi, penyimpanan, distribusi dan pemasaran menjadi hal utama dalam menjamin penerapan manajemen rantai pasok.(Hall \& Saygin, 2012)

\subsection{Kolaborasi Digital}

Pada era teknologi informasi saat ini, pelaku UMKM harus bisa menyesuaikan diri dalam pengelolaan sumber dayanya supaya tidak semakin tertinggal dari kompetitor. Mengikuti perkembangan teknologi informasi, para pelaku UMKM harus sadar bahwa saat ini sudah tidak jamannya lagi mengedepankan kompetisi namun perlu lebih mempertimbangkan potensi kolaborasi. Digital Collaboration Networks (DCN) adalah sebuah ekosistem digital yang telah di rancang untuk memfasilitasi kolaborasi dan koalisi bisnis antar pelaku ekonomi sebuah industri dalam bentuk virtual. Bentuk kolaborasi tersebut diwujudkan dalam bentuk sharing knowledge dan business resources untuk membentuk aplikasi aplikasi bisnis yang lebih kompleks berdasar pada servis inti dari tiap penyedia demi meningkatkan daya saing industri (Fachrunnisa, 2013).

Organisasi harus membangun strategi yang lebih cepat dan efisien dengan membentuk strategic partnerships dan aliansi, rekayasa dan mengintegrasikan semua proses bisnisnya untuk mengembangkan nilai tambah produk dan jasa, serta mampu membagi pengetahuan dan pengalaman kepada sesama organisasi lain dalam sebuah jaringan (Fachrunnisa \& Adhiatma, 2016). Pelaku UKM perlu melakukan kolaborasi untuk meingkatkan daya saing, terlebih lagi dengan kolaborasi digital segala potensi kolaborasi dapat lebih mudah diimplementasikan. Kunci dalam melakukan kolaborasi adalah keterbukaan informasi antar pelaku UKM, saling percaya antar phak serta kesamaan harapan dalam saling berkolaborasi (Fachrunnisa et al., 2013).

Hal ini telah banyak di tegaskan di beberapa literature bahwa organisasi jaringan adalah bentuk baru sebuah struktur organisasi yang sangat menguntungkan. Organisasi berbentuk jaringan sebagai sekumpulan perusahaan atau individu yang bertindak selaku nodes yang bebas, terhubung tanpa batas, bekerja sama untuk mencapai tujuan bersama; memiliki banyak pemimpin, memiliki banyak link link yang secara sukarela digunakan untuk membagi pengetahuan dan ketrampilan. (Fachrunnisa, 2013) 
Rancang Bangun Sistem Kolaborasi UKM Berdasarkan Manajemen Rantai Pasok untuk Peningkatan Daya Saing UMKM Kota Semarang

Seiring berjalannya waktu, pembentukan link virtual ini pada akhirnya akan menembus batas waktu dan letak geografis yang memungkinkan sebuah perusahaan untuk membentuk supply chain industri lintas Negara. Inovasi struktur organisasi ini akan membentuk sebuah organisasi jaringan dan jaringan pasar baru. Bentuk baru ini bisa dinamakan sebagai dynamic customer-centered networks. Sebagai dampak dari adanya organisasi berbentuk jaringan ini, maka networking yang dinamis di antara para pelaku industri akan mendorong kerjasama dan kolaborasi para pemain inti sebuah industri. Hubungan bentuk bentuk kolaborasi ini juga menghubungkan sumber daya sumber daya bisnis mereka dalam sebuah system. Untuk itulah maka kemudian muncul untuk meyakini sebuah ide digital ekosistem sebagai bentuk baru sarana pelaku industri untuk terkoneksi secara virtual serta kemampuan membentuk kolaborasi bisnis tanpa batasan waktu dan tempat.

Sesuai dengan Renstra Menkop dan UKM dimana salah satu poin nya menyebutkan bahwa pemanfaatan teknologi khususnya IT dapat diaplikasikan untuk meningkatkan akses kepada sumber daya produktif, yaitu akses teknologi, bahan baku dan permodalan dan poin yang berikutnya: mengembangkan dan meningkatkan kuantitas informasi UKM, termasuk pengembangan system dan jaringan informasinya (Kementerian Koperasi dan UKM, 2010), maka model kolaborasi bisnis ini sudah selayaknya mulai dikembangkan di Indonesia.

\section{PEMBAHASAN}

\subsection{Kolaborasi UMKM Berdasarkan Mata Rantai Pasok}

\section{a. Pentingnya Berkolaborasi Antar Palaku UMKM}

Berdasarkan tanggapan

Pentingnya Kolaborasi Antar Sesama Pelaku UMKM, sebaran responden pada penelitian ini lebih dominan dengan tanggapan penting yaitu mencapai 45 tanggapan ( 80\%). Grafik sebaran responden ditunjukan pada pada Gambar 1.

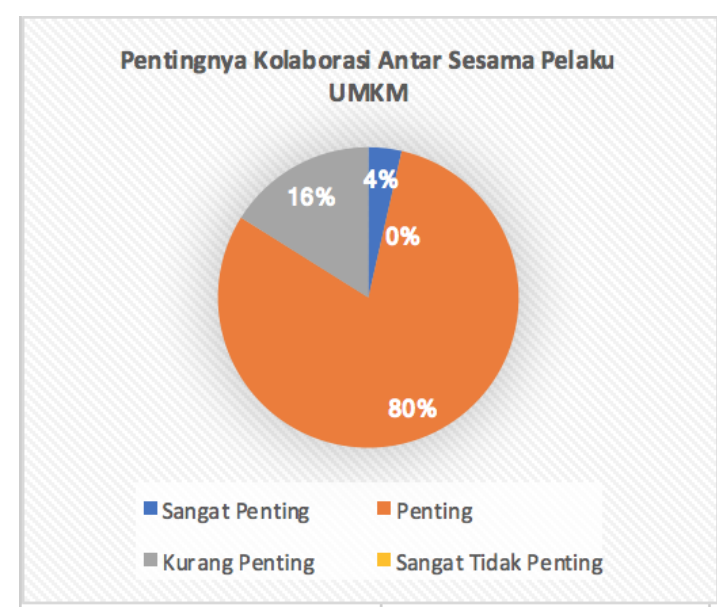

Gambar 1. Grafik sebaran responden berdasarkan pentingnya kolaborasi antar sesama pelaku UMKM

\section{b. Minat Kolaborasi berdasarkan kesamaan pemasok}

Berdasarkan minat kolaborasi pemasok produk yang sama, sebaran responden pada penelitian ini lebih dominan dengan tanggapan setuju yaitu mencapai 43 tanggapan ( 84\%). 
Sebaran responden ditunjukan pada Gambar 2.

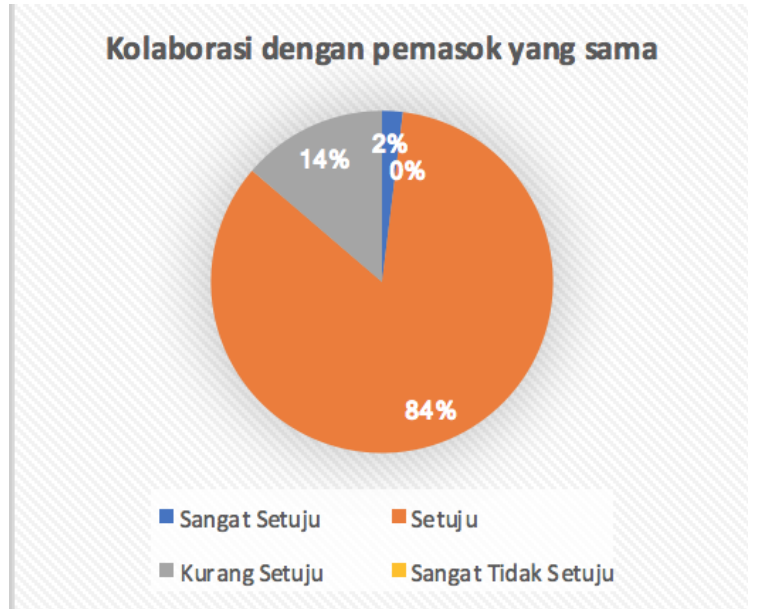

Gambar 2 Grafik sebaran responden berdasarkan minat kolaborasi pemasok produk yang sama

\section{c. Kolaborasi antar pelaku UMKM akan meningkatkan efisiensi produksi}

Tanggapan responden terhadap pemahaman bahwa kolaborasi akan meningkatkan efisiensi produksi ditunjukan pada Gambar 3.

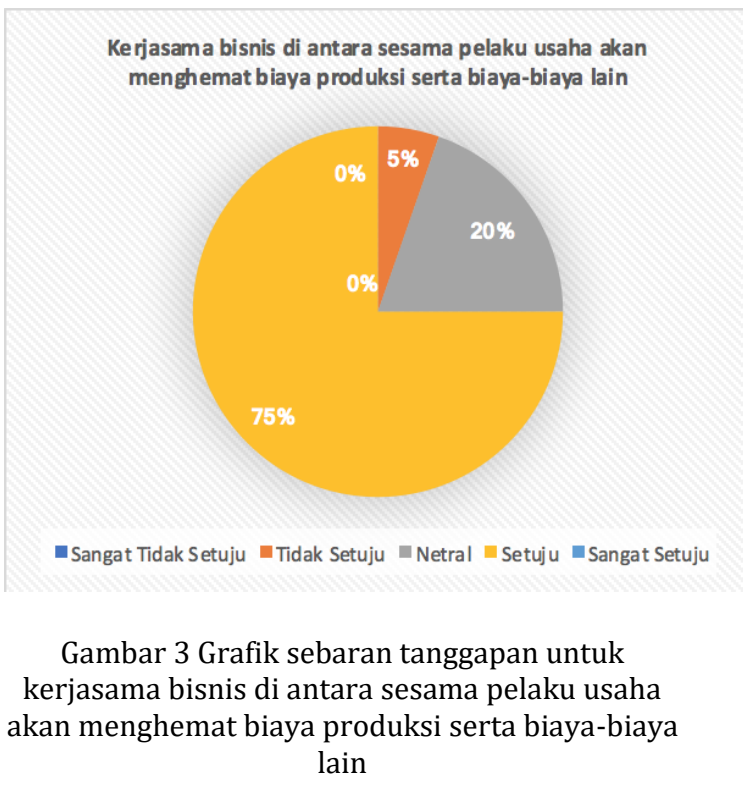

\subsection{Model Kolaborasi Berdasarkan Mata Rantai Pasok}

Hasil dari penelitian ini untuk bisa melakukan kolaborasi berdasarkan mata rantai pasaok secara efektif dan berkelanjutan para pelaku UMKM perlu memperhatikan beberapa hal sebagai berikut:

\section{- Keterbukaan Informasi}

Keterbukaan informasi disesuaikan dengan potensi dan kebutuhan kolaborasi antar UMKM. Sebagai contoh untuk kolaborasi pada proses pengadaan dalam penentuan supplier ataupun evaluasi kinerja supplier maka antar pelaku UMKM yang hendak berkolaborasi perlu ada keterbukaan informasi terhadap kebutuhan supply bahan baku, kualitas, kuantitas, kapasitas produksi serta informasi data supplier. Melalui keterbukaan informasi tersebut maka harapan melakukan kolaborasi secara berkelanjutan dapat berjalan dengan baik.

- Menjalin hubungan atas dasar saling percaya

Untuk membangun kolaborasi yang berkelanjutan, para pihak pelaku UMKM perlu mengedepankan hubungan kolaborasi atas dasar saling percaya.

\section{- Mengoptimalkan Teknologi} Informasi

Layanan teknologi informasi perlu dioptimalkan oleh pelaku UMKM untuk mempermudah sarana komunikasi dan saling bertukar informasi. Perlu 
Rancang Bangun Sistem Kolaborasi UKM Berdasarkan Manajemen Rantai Pasok untuk Peningkatan Daya Saing UMKM Kota Semarang

dipersiapkan sistem informasi kolaborasi berdasarkan mata rantai pasok yang di desain sejak awal dengan melibatkan semua stakeholder selain mengoptimalkan layanan aplikasi komunikasi seperti Wahtsapp, Email ataupun telegram.

\section{- Potensi Kolaborasi}

Berdasarkan mata rantai pasok, potensi kolaborasi antar UMKM diantaranya : pengelolaan supplier, jaringan distribusi baik pada sisi supplier maupun pada sisi pemasaran, manajemen hubungan dengan pelanggan, penguatan kelembagaan, dll.

\subsection{Rancang Bangun SIstem Kolaborasi}

\subsubsection{Use Case Diagram}

Diagram use case untuk

Sistem ditunjukan Gambar 4.

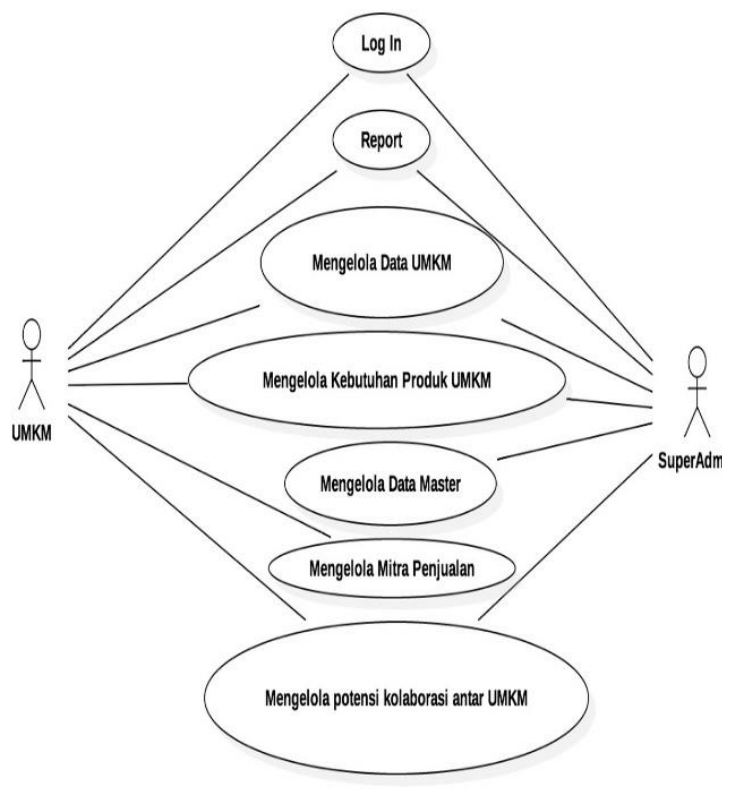

Gambar 4. Diagram Use Case

\subsubsection{Desain Database}

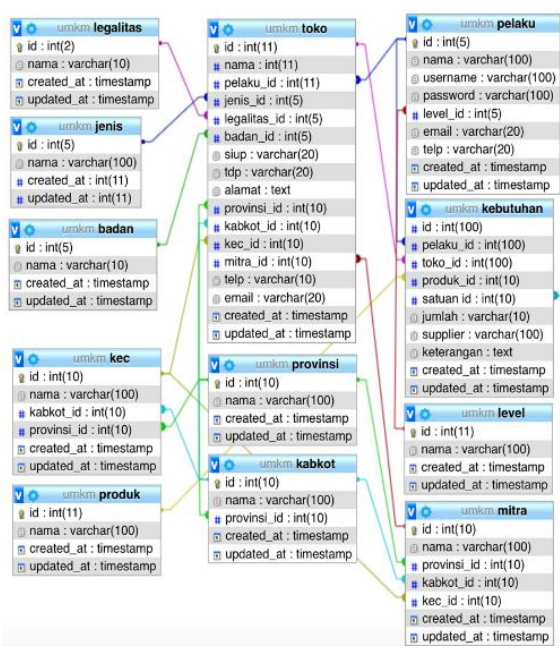

Gambar 5. Desain database

\subsubsection{Activity Diagram}

a. Activity diagram super admin melakukan login

Untuk masuk dan mengelola sistem, Super Admin harus melakukan login. Activity Diagram super admin melakukan login di tunjukkan pada Gambar 6

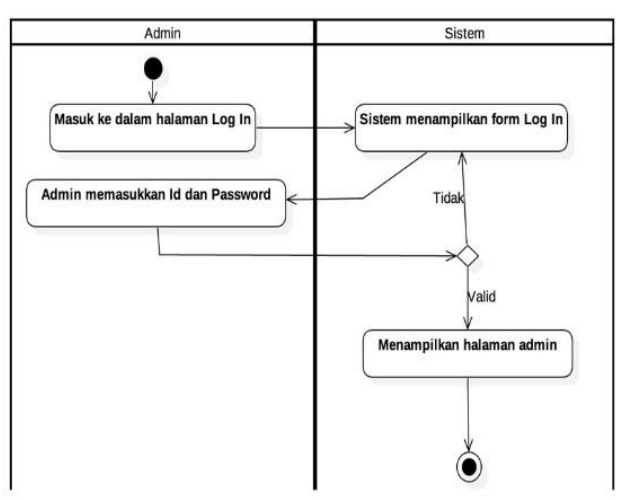

Gambar 6. Activity Diagram Super Admin melakukan login 
b. Activity diagram super admin melihat laporan kebutuhan UMKM

Untuk melihat laporan kebutuhan UMKM, Super Admin harus melakukan login terlebih dahulu, dan kemudian masuk ke halaman laporan kebutuhan UMKM. Activity Diagram super admin melihat laporan kebutuhan UMKM di tunjukkan pada gambar 7.

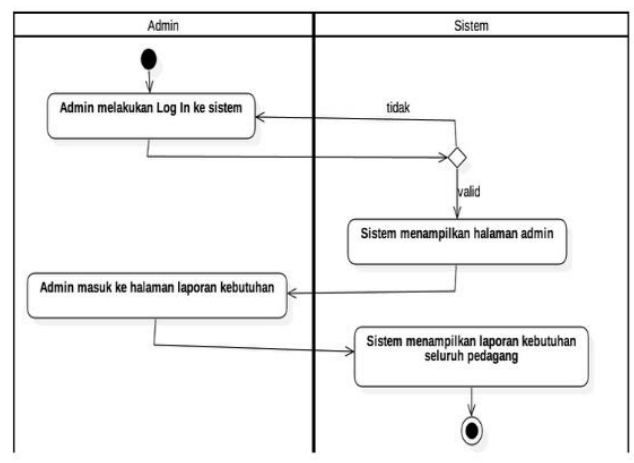

Gambar 7. Activity Diagram Super Admin melihat laporan kebutuhan UMKM

c. Activity diagram super admin mengelola data UMKM

Untuk mengelola data UMKM, Super Admin harus melakukan login terlebih dahulu, dan kemudian masuk ke halaman data UMKM. Activity Diagram super admin mengelola data UMKM di tunjukkan pada Gambar 8

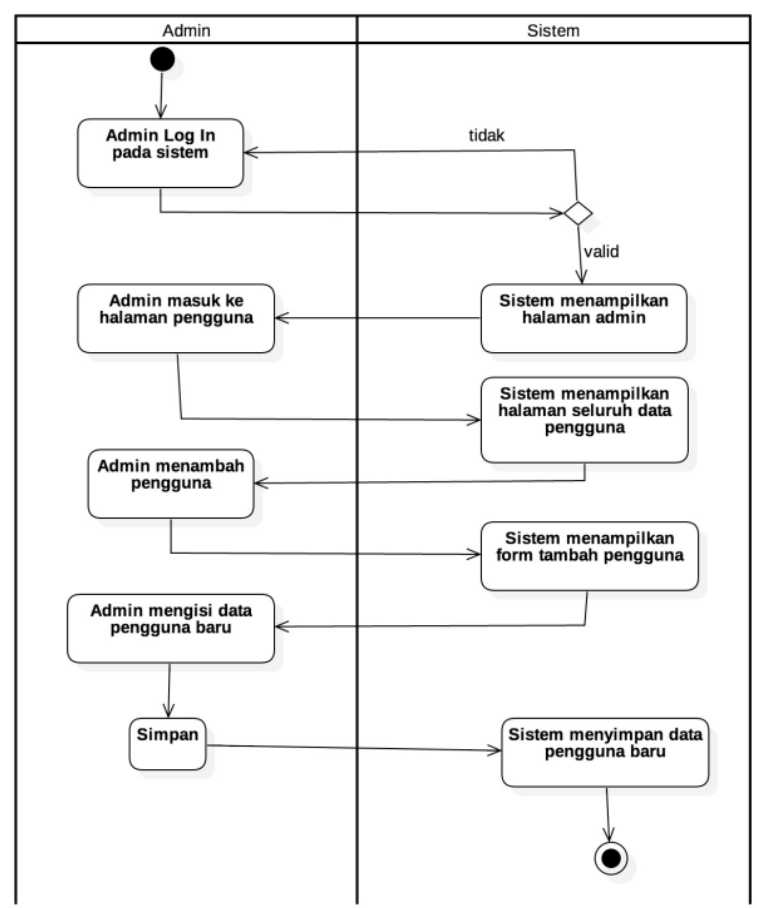

Gambar 8. Activity Diagram Super Admin mengelola data UMKM

d. Activity diagram super admin mengelola kebutuhan produk UMKM

Untuk mengelola kebutuhan produk UMKM, Super Admin harus melakukan login terlebih dahulu, dan kemudian masuk ke halaman tambah data kebutuhan UMKM. Activity Diagram super admin mengelola kebutuhan produk UMKM di tunjukkan pada Gambar 9 
Rancang Bangun Sistem Kolaborasi UKM Berdasarkan Manajemen Rantai Pasok untuk Peningkatan Daya Saing UMKM Kota Semarang

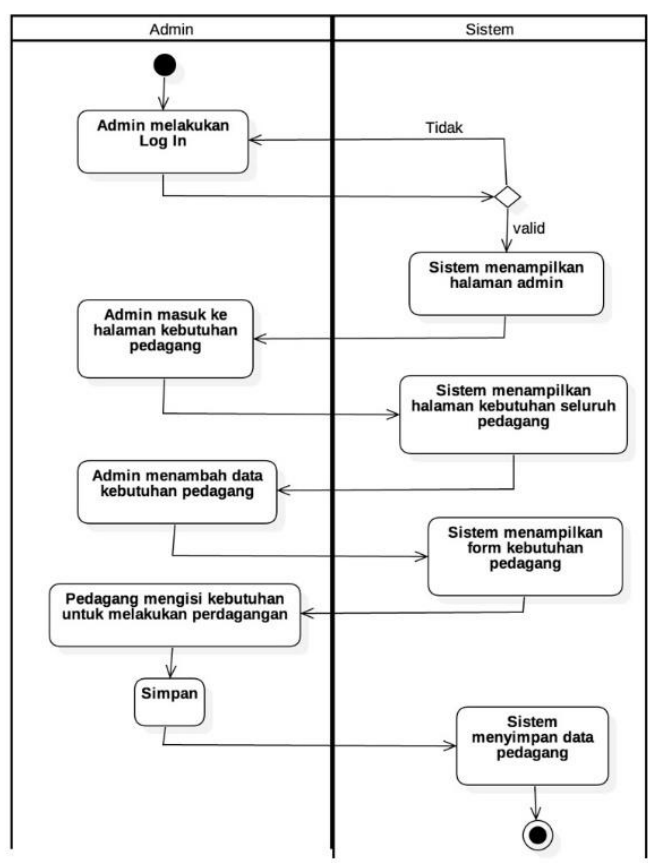

Gambar 9. Activity Diagram Super Admin mengelola kebutuhan produk UMKM

e. Activity diagram super admin mengelola data master

Untuk mengelola data master, Super Admin harus melakukan login terlebih dahulu, dan kemudian masuk ke halaman data master. Activity Diagram super admin mengelola data master di tunjukkan pada Gambar 10

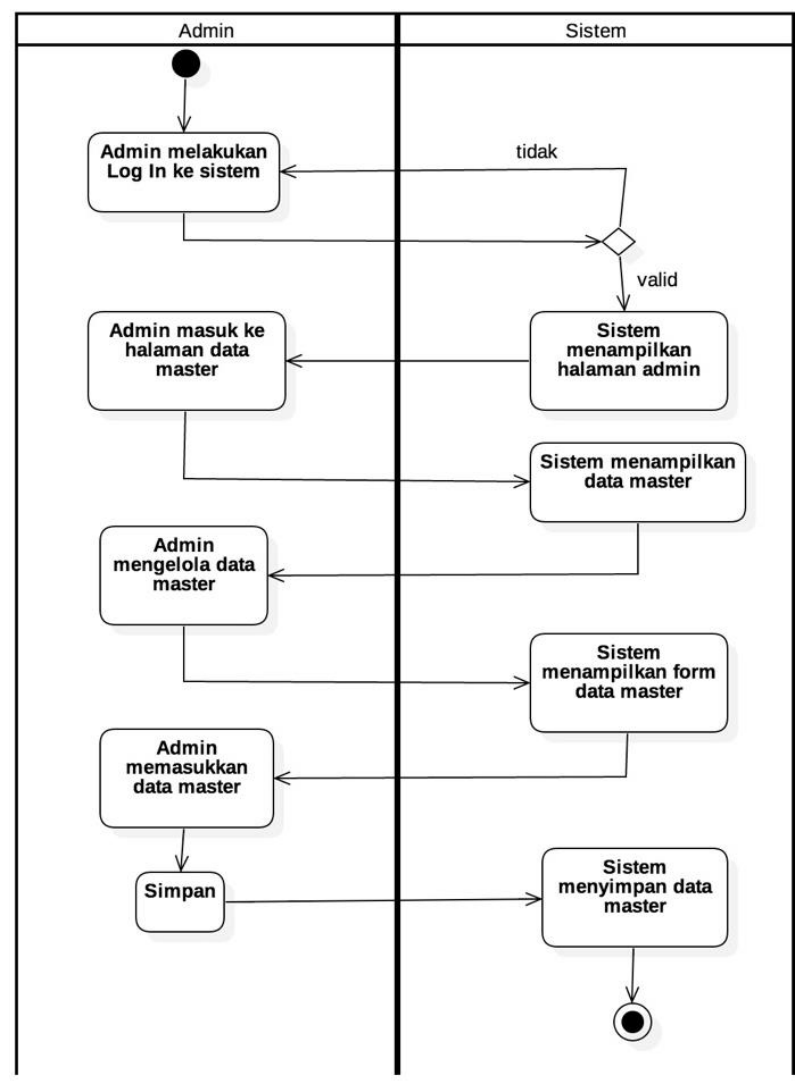

Gambar 10. Activity Diagram Super Admin mengelola data master

f. Activity diagram super admin mengelola data potensi kolaborasi antar UMKM

Untuk mengelola potensi kolaborasi antar UMKM, Super Admin harus melakukan login terlebih dahulu, dan kemudian masuk ke halaman informasi kebutuhan pasar. Activity Diagram super admin mengelola data master di tunjukkan pada Gambar 11. 


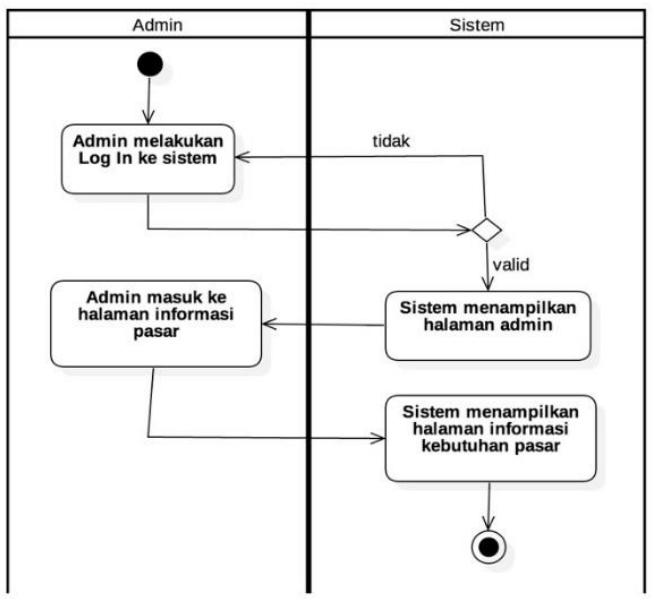

Gambar 11. Activity Diagram Super Admin mengelola potensi kolaborasi antar UMKM

\subsection{User Interface}

a. Halaman Awal Umum

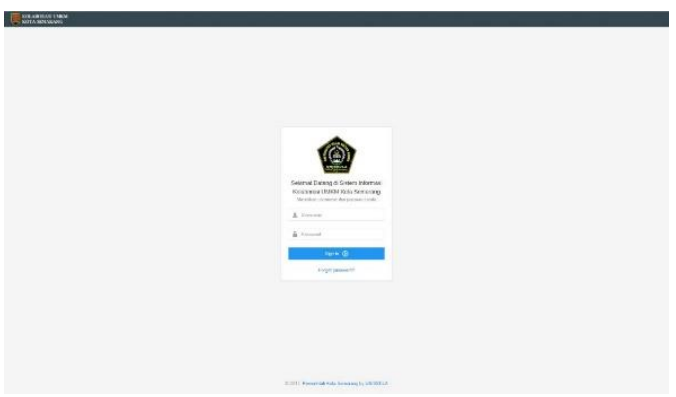

b. Halaman UMKM

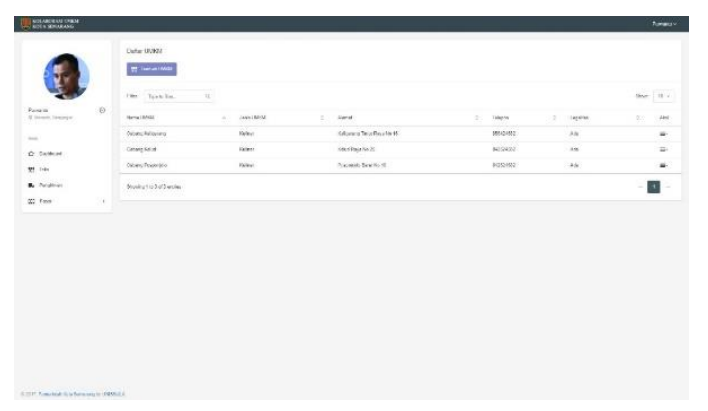

c. Halaman tambah UMKM
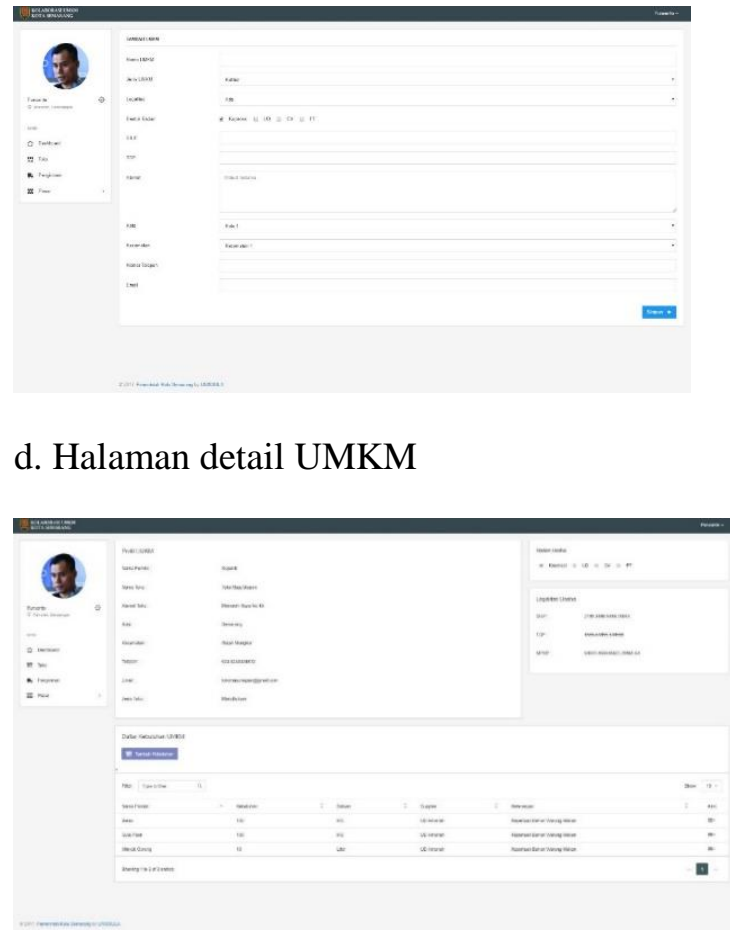

e. Halaman tambah produk UMKM

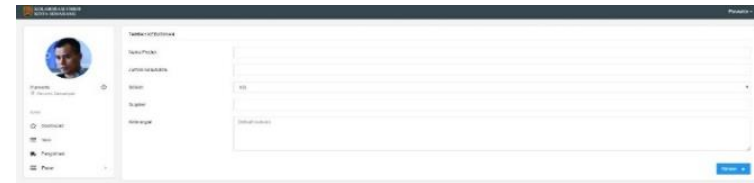

e. Halaman list kolaborasi sesuai produk UMKM

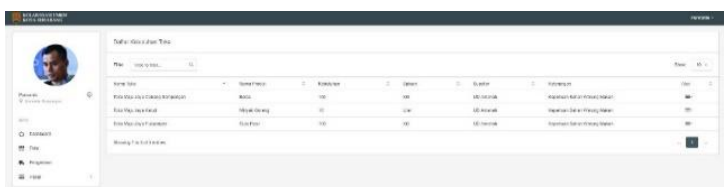


Rancang Bangun Sistem Kolaborasi UKM Berdasarkan Manajemen Rantai Pasok untuk Peningkatan Daya Saing UMKM Kota Semarang

\subsection{Pengujian}

Pengujian sistem dilakukan oleh peneliti menggunakan metode blackbox test. Pengujian ini dilakukan sebelum sistem kolaborasi UKM ini dapat diimplementasikan.
Berdasarkan hasil pengujian sistem dapat disimpulkan bahwa sistem dapat berjalan dengan baik. Tabel pengujian dapat dilihat pada Tabel 1 .

Tabel 1. Hasil pengujian sistem

\begin{tabular}{|c|c|c|c|c|}
\hline NO & Deskripsi pengujian & $\begin{array}{l}\text { Hasil yang } \\
\text { diharapkan }\end{array}$ & $\begin{array}{c}\text { Hasil Yang } \\
\text { didapat }\end{array}$ & Keterangan \\
\hline 1 & $\begin{array}{l}\text { Pendaftaran pelaku } \\
\text { UKM }\end{array}$ & $\begin{array}{l}\text { Bisa mendaftar } \\
\text { dan login dalam } \\
\text { sistem }\end{array}$ & $\begin{array}{l}\text { Pendaftaran } \\
\text { berjalan lancar }\end{array}$ & $\mathrm{OK}$ \\
\hline 2 & $\begin{array}{l}\text { Update profil pelaku } \\
\text { UKM }\end{array}$ & $\begin{array}{l}\text { UKM bisa update } \\
\text { profil }\end{array}$ & $\begin{array}{l}\text { UKM bisa update } \\
\text { profil }\end{array}$ & $\mathrm{OK}$ \\
\hline 3 & $\begin{array}{l}\text { Dashboard potensi } \\
\text { kolaborasi antar UKM }\end{array}$ & $\begin{array}{l}\text { UKM bisa } \\
\text { melihat potensi } \\
\text { kolaborasi } \\
\text { dengan palaku } \\
\text { UKM lain }\end{array}$ & $\begin{array}{l}\text { UKM bisa melihat } \\
\text { data potensi } \\
\text { pelaku UKM yang } \\
\text { dapat } \\
\text { berkolaborasi }\end{array}$ & $\mathrm{OK}$ \\
\hline
\end{tabular}

\section{PENUTUP}

Kesimpulan dari penelitian ini adalah para pelaku UMKM Kota Semarang pada dasarkan sebagian besar setuju bahwa kolaborasi dengan pelaku UMKM lain akan meningkatkan daya saing namun ada sebagian yang kurang setuju jika kolaborasi tersebut dilegalkan ke dalam bentuk koperasi.

Hasil penelitian terhadap 55 responden UMKM di Kota Semarang menghasilkan bahwa sebanyak 44 responden (80\%) mengatakan setuju untuk meningkatkan daya saing perlu melakukan kolaborasi terutama dengan UMKM dengan bidang usaha yang sama. Sebanyak 47 responden $(85,5 \%)$ mengatakan bahwa kolaborasi antar UMKM penting untuk meningkatkan daya saing UMKM Kota Semarang.

Model kolaborasi yang paling utama berdasarkan manajemen rantai pasok terletak pada potensi kolaborasi proses pemenuhan bahan baku masing-masing UMKM. Sistem kolaborasi UKM dapat berjalan dengan baik namun untuk bisa lebih mempermudah penggunaan dan memberi manfaat maksimal perlu dikembangkan sistem berbasis aplikasi mobile. Fitur lain yang dibutuhkan dalam sistem kolaborasi adalah adanya layanan untuk berkomunikasi dengan pelaku UKM lain didalam sistem sehingga dapat terdokumentasi dengan baik. 


\section{REFFERENCES}

Fachrunnisa, O. (2013). Digital Collaboration Network for SMEs: Awareness of ICT and Perceived Outcome. 2013 Seventh International Conference on Complex, Intelligent, and Software Intensive Systems, 40-46. https://doi.org/10.1109/CISIS.2013.17

Fachrunnisa, 0., \& Adhiatma, A. (2016). Social Identity, Collective Engagement and Communal Patent For Successful Digital Collaboration. August, 29-30.

Fachrunnisa, O., Mutamimah, \& Gunawan. (2013). Trust, Self Regulation and Social Movement:Partner Selection at Digital Collaboration Network forSME's Sustainability. International Journal of Trade, Economics and Finance, 3(6), 412420. https://doi.org/10.7763/IJTEF.2012.V3.237

Hall, D. C., \& Saygin, C. (2012). Impact of information sharing on supply chain performance. International Journal of Advanced Manufacturing Technology, 58(1-4), 397-409. https://doi.org/10.1007/s00170-011-3389-0

Hayati, E. N. (2015). Supply Chain Management (Scm) Dan Logistic Management. Jurnal Ilmiah Dinamika Teknik, 8(1), 25-34. http://www.unisbank.ac.id/ojs/index.php/ft1/article/view/3039/828

Wahyuniardi, R., Afrianti, L. H., Nurjaman, S., \& Gusdya, W. (2016). Pembangunan Sistem Informasi Berbasis Web Untuk Monitoring Dan Evaluasi Sentra Industri Kecil Dan Menengah Di Jawa Barat. Jurnal Ilmiah Teknik Industri, 4(1), 9-19. https://doi.org/10.23917/jiti.v16i2.xxxx 